\title{
Poststroke epilepsy: current perspectives on diagnosis and treatment
}

This article was published in the following Dove Medical Press journal:

Neuropsychiatric Disease and Treatment

\section{Beata Sarecka-Hujar' Ilona Kopyta ${ }^{2}$}

'Department of Pharmaceutical Technology, School of Pharmacy with the Division of Laboratory Medicine in Sosnowiec, Medical University of Silesia in Katowice, Sosnowiec, Poland; ' 2 Department of Paediatric Neurology, School of Medicine in Katowice, Medical University of Silesia in Katowice, Katowice, Poland
Correspondence: Beata Sarecka-Hujar Department of Pharmaceutical Technology, School of Pharmacy with the Division of Laboratory Medicine, Medical University of Silesia in Katowice, ul

Kasztanowa 3, 4I-200 Sosnowiec, Poland

$\mathrm{Tel}+48322699820$

$\mathrm{Fax}+48322699821$

Email beatasarecka@poczta.onet.pl

\begin{abstract}
Seizures and epilepsy are quite a common outcome of arterial ischemic stroke (AIS) both in pediatric and adult patients, with distinctly higher occurrence in children. These poststroke consequences affect patients' lives, often causing disability. Poststroke seizure (PSS) may also increase mortality in patients with AIS. Early PSS (EPSS) occurring up to 7 days after AIS, late PSS (LPSS) occurring up to 2 years after the onset of AIS, as well as poststroke epilepsy (PSE) can be distinguished. However, the exact definition and cutoff point for PSE should be determined. A wide range of risk factors for seizures and epilepsy after AIS are still being detected and analyzed. More accurate knowledge on risk factors for PSS and PSE as well as possible prediction of epileptic seizures after the onset of AIS may have an impact on improving the prevention and treatment of PSE. The aim of the present review was to discuss current perspectives on diagnosis and treatment of PSS and PSE, both in adult and paediatric patients. Keywords: arterial ischemic stroke, early seizures, late seizures, antiepileptic treatment
\end{abstract}

\section{Introduction}

The role of cerebrovascular disorders is observed in the development of $11 \%$ of all cases of epilepsy. ${ }^{1}$ The nature of some of these diseases, including arterial ischemic stroke (AIS), causes many primary and secondary changes that can initiate epileptogenesis. AIS as a quite frequent disorder in adulthood carries serious and devastating neurological consequences that affect all aspects of patients' lives, often preventing them from leading an independent existence. In turn, ischemic stroke is a rare disease in pediatric population. However, the consequences are equally serious and even detrimental because the period of education and puberty is then strongly disturbed. Seizures and epilepsy are one of the most common poststroke outcomes, both in adults and children. However, seizures after stroke are reported more frequently in children than in adults. It was observed that the relative risk of seizure occurring within 24 hours after stroke was 18 times higher in pediatric patients than in adults. ${ }^{2}$

In patients $>60$ years of age, almost $50 \%$ of seizures occur for the first time in their life as a consequence of ischemic stroke. ${ }^{3}$ Poststroke seizure (PSS) increases mortality in patients (both short term and long term), disability at discharge, as well as extended hospital stay. ${ }^{4}$ The mortality rate in patients with PSS was found to be at a higher level than in all patients with ischemic stroke. ${ }^{5}$ However, results from a study based on Italian patients showed that early seizures were not related to increased mortality or disability. ${ }^{6}$ Similarly, in children with AIS from Taiwan, PSS did not affect mortality. ${ }^{7}$ Early poststroke seizure (EPSS) was demonstrated to be more common in the case of cerebral hemorrhage than in the case of cerebral infarction. ${ }^{8}$ Although data showing opposite results are also available. ${ }^{9}$ submit your manuscript | www.dovepress.com 
Thus, due to all these discrepancies, more accurate knowledge on risk factors for PSS and epilepsy as well as the possibility to predict the occurrence of epileptic seizures may have an impact on improving the prevention and treatment of poststroke epilepsy (PSE). Prophylaxis with antiepileptic drugs (AEDs) for a defined period of time is in the field of special interests.

The aim of the present review was to discuss current perspectives on diagnosis and treatment of epilepsy that may occur after AIS, both in adult and pediatric patients.

\section{Prevalence of PSS and PSE in children and adults}

The length of the follow-up period of stroke patients can be an indicator of the prevalence of PSE - the longer the follow-up, the higher the frequency of epilepsy after stroke. Despite that, the prevalence of PSS as well as PSE differs between populations, both in adults and pediatric patients. The prevalence of PSE in adult patients suffering from AIS has been shown to range from $2 \%$ to $4 \% .{ }^{10}$ The frequency of PSS in adult patients is more or less at a similar level in different populations (Table 1). In a French study, 6.9\% of patients with stroke had late poststroke seizure (LPSS), and a similar prevalence of late seizures was found by Roivainen et al in Finnish patients (6.1\%). ${ }^{11,12}$ EPSS was distributed as follows: in French patients - 5.4\%, in Finnish patients - 3.5\%, and in Danish patients $-4.2 \% .{ }^{11-13}$ Surprisingly, in patients with stroke (ischemic and hemorrhagic strokes were analyzed jointly) from Rajasthan, the frequency of EPSS and LPSS was especially high ( $54 \%$ and $46 \%$, respectively) when compared to other data. ${ }^{14}$ The prevalence of PSE ranges from $1.6 \%$ in
Taiwan population ${ }^{15}$ to $8.2 \%$ in German population. ${ }^{16}$ However, only the study by Kammersgaard and Olsen ${ }^{13}$ gave the exact definition of PSE, whereas in the study by Jungelhulsing et al, ${ }^{16}$ the patients were diagnosed as epileptic when they had at least one late poststroke epileptic seizure $<2$ years after initial stroke.

Table 2 shows the frequency of epileptic seizures appearing after ischemic stroke and PSE in pediatric populations. Compared to adult patients, the frequency of both seizures and epilepsy is higher in children. Available data on children stroke revealed that the lowest frequency of PSS, both early (17\%) and late (9\%), was observed in the study analyzing children hospitalized at a university medical center in southern Poland. ${ }^{17}$ A similar prevalence of acute symptomatic seizure appearing $\leq 7$ days after stroke and remote symptomatic seizures was demonstrated in the study by Billinghurst et al, who retrospectively analyzed 105 patients with childhood stroke hospitalized at Children's Hospital of Philadelphia, USA. ${ }^{18}$ However, surprisingly in this study, the percentages of patients with childhood AIS and PSE were almost twice lower than in the study by Kopyta et al (7\% vs $13 \%$, respectively). ${ }^{17}$ On the other hand, another study conducted in Poland, but in northern part, showed that the prevalence of cases with epilepsy was similar (14.6\%) to the one reported in the study by Kopyta et al and defined early seizures as those occurring during the first 24 hours after stroke. However, it did not demonstrate the frequency of LPSS. ${ }^{19}$ Almost the same frequency of PSE was also observed in Iranian children (16\%). ${ }^{20} \mathrm{~A}$ greater prevalence of PSS was in turn observed in the group of patients from the Netherlands and Korea (26\% and $32.3 \%$, respectively), and particularly

Table I Prevalence of PSS and PSE in adult patients with AIS

\begin{tabular}{|c|c|c|c|}
\hline Study & Population & Frequency of PSS & Frequency of PSE \\
\hline Cordonnier et al" & $\begin{array}{l}\text { Patients hospitalized in Lille University } \\
\text { Hospital (France); median age } 75 \text { years }\end{array}$ & $\begin{array}{l}\text { Early seizures }-5.4 \% \\
\text { Late seizures }-6.9 \%\end{array}$ & NA \\
\hline Roivainen et al ${ }^{12}$ & $\begin{array}{l}\text { Patients from Finland with their first } \\
\text { ischemic stroke; aged I5-49 years }\end{array}$ & $\begin{array}{l}\text { Early seizures }-3.5 \% \\
\text { Late seizures }-6.1 \% \text { at I year, } \\
9.5 \% \text { at } 5 \text { years, and II.5\% at } 10 \text { years }\end{array}$ & NA \\
\hline $\begin{array}{l}\text { Kammersgaard } \\
\text { and Olsen }{ }^{13}\end{array}$ & Patients from Denmark & $\begin{array}{l}\text { Early seizures }-4.2 \% \\
\text { Late seizures - NA }\end{array}$ & $3.2 \%$ \\
\hline Kamble et al ${ }^{14}$ & $\begin{array}{l}\text { Department of Neurology in } \\
\text { Kota (Rajasthan); mean age } 57.6 \pm 15 \text { years }\end{array}$ & $\begin{array}{l}\text { Early seizures }-54 \% \\
\text { Late seizures }-46 \%\end{array}$ & NA \\
\hline Chen et $\mathrm{al}^{15}$ & $\begin{array}{l}\text { Adults from Taiwan; mean age of patients } \\
\text { with AIS } 64.8 \pm 10.6 \text { years }\end{array}$ & NA & $1.6 \%$ \\
\hline Jungehulsing et $\mathrm{al}^{16}$ & $\begin{array}{l}\text { Patients hospitalized in Center for } \\
\text { Stroke Research Berlin (Germany); } \\
\text { age ranged from } 65 \text { to } 85 \text { years }\end{array}$ & NA & $8.2 \%$ \\
\hline
\end{tabular}

Note: alschemic stroke was analyzed jointly with hemorrhagic stroke.

Abbreviations: AIS, arterial ischemic stroke; NA, not available; PSE, poststroke epilepsy; PSS, poststroke seizure. 
Table 2 Prevalence of PSS and PSE in pediatric patients with AIS

\begin{tabular}{|c|c|c|c|}
\hline Study & Population & Frequency of PSS & $\begin{array}{l}\text { Frequency } \\
\text { of PSE }\end{array}$ \\
\hline Kopyta et al ${ }^{17}$ & $\begin{array}{l}\text { Polish children (southern Poland); } \\
\text { age range: I month to } 18 \text { years }\end{array}$ & $\begin{array}{l}\text { Early seizures }-17 \% \\
\text { Late seizures }-9 \%\end{array}$ & $13 \%$ \\
\hline Billinghurst et al ${ }^{18}$ & $\begin{array}{l}\text { Children hospitalized at the Children's } \\
\text { Hospital of Philadelphia (USA) }\end{array}$ & $\begin{array}{l}\text { Acute symptomatic seizures occurring } \leq 7 \text { days after } \\
\text { stroke }-17 \% \text {, remote symptomatic seizures }-10 \%\end{array}$ & $7 \%$ \\
\hline Pilarska and Lemka ${ }^{19}$ & $\begin{array}{l}\text { Polish children (northern Poland); } \\
\text { aged 2-16 years }\end{array}$ & Early seizures $-7.3 \%$ & $14.6 \%$ \\
\hline Nasiri et $\mathrm{a}^{20}$ & $\begin{array}{l}\text { Children from Iran; mean age at first } \\
\text { stroke was } 5.2 \text { years }\end{array}$ & NA & $16 \%$ \\
\hline Lee et $\mathrm{al}^{21}$ & $\begin{array}{l}\text { Korean children; age range: I month } \\
\text { to } 17 \text { years }\end{array}$ & $32.3 \%$ & $20 \%$ \\
\hline De Schryver et $\mathrm{al}^{22}$ & $\begin{array}{l}\text { Children from the Netherlands; } \\
\text { aged }<16 \text { years }\end{array}$ & $26 \%$ & NA \\
\hline Morais et $\mathrm{al}^{23}$ & Brazilian children; aged $<18$ years & $\begin{array}{l}64.6 \% \text {, including early seizures }-53.8 \% \text {, late } \\
\text { seizures }-10.8 \%\end{array}$ & $29.2 \%$ \\
\hline Breitweg et $\mathrm{al}^{24}$ & $\begin{array}{l}\text { Children and adolescents from Germany; } \\
\text { aged up to } 18 \text { years }\end{array}$ & Early seizures $-20.5 \%^{a}$ & $27 \%^{\mathrm{a}}$ \\
\hline Fox et $\mathrm{a}^{25}$ & $\begin{array}{l}\text { Children with stroke enrolled in the } \\
\text { Northern California Kaiser Permanente (USA) }\end{array}$ & Remote seizures $-49 \%$ & NA \\
\hline
\end{tabular}

Note: alschemic stroke was analyzed jointly with hemorrhagic stroke.

Abbreviations: AIS, arterial ischemic stroke; NA, not available; PSE, poststroke epilepsy; PSS, poststroke seizure.

high frequencies of PSS and epilepsy were found in Brazilian children with AIS (64.6\% and $29.2 \%$, respectively). ${ }^{21-23} \mathrm{In}$ a Brazilian study, over half of the stroke children had early seizures and seizures evolved into epilepsy in almost $30 \%$ of pediatric patients. In the study by Breitweg et al, ${ }^{24}$ early seizures were present in $>20 \%$ of children with stroke and PSE in $27 \%$ of patients. Moreover, in the study by Fox et al, ${ }^{25}$ almost half of the children with AIS had remote seizures.

\section{Clinical presentation of PSS}

Cordonnier et al $^{11}$ observed in adult patients that EPSS was simple partial (in five patients), generalized tonic-clonic without signs of focal onset (in three patients), and one patient had secondary generalized seizures. The same presentations were also found in the case of LPSS. Conrad et $\mathrm{al}^{26}$ showed that in almost $41 \%$ of patients, seizures were classified as partial (most of them were simple partial), and 57\% patients had generalized seizures. However, there are also patients in whom the type of seizure cannot be determined. ${ }^{11,26}$ The frequency of status epilepticus differs between populations and was found to be present in $16.7 \%$ of cases as well as in only $9 \%$ of patients. ${ }^{26,27}$

In the case of PSE in children, Kopyta et al demonstrated that all of the analyzed pediatric patients with PSS $(n=20)$ had seizures, which were focal in nature. However, in $40 \%$ of them, seizures were secondary generalized. ${ }^{17}$
In the study by Pilarska and Lemka, 7\% of analyzed children with AIS had EPSS, which were generalized tonic-clonic and were observed within the first 24 hours after stroke. ${ }^{19}$ In turn, in the group with neonatal AIS from Philadelphia, most patients had either subtle or multifocal clonic seizures, whereas in the group with childhood stroke, almost all children with epilepsy had seizures focal in nature with or without secondary generalization, except one child who had infantile spasms. ${ }^{18}$

\section{Diagnosis of PSS and PSE}

The definitions and classifications of seizures and epilepsy have a long history. However, the seizure classification, which was updated in $1981^{28}$ by introducing the following terms: "complex partial", "simple partial", "generalized", and "unclassifiable", was also maintained in the discussion of the International League Against Epilepsy (ILAE) in 2010 with only minor changes. ${ }^{29}$ According to the definition, which was updated in 2005 and maintained in 2014, an epileptic seizure is "a transient occurrence of signs and/or symptoms due to abnormal excessive or synchronous neuronal activity in the brain". ${ }^{30}$

In turn, epilepsy is diagnosed in an individual who has at least two unprovoked or reflex seizures or one unprovoked or reflex seizure and $\geq 60 \%$ likelihood of having subsequent seizures over the next 10 years or an epilepsy syndrome. ${ }^{30}$ The patient's brain after the first epileptic 
seizure demonstrates a pathological and enduring tendency for recurrent seizures. ${ }^{30}$

The current definition of epilepsy as well as the division of epileptic seizures recommended by ILAE have been used since 2014, so the studies published before that time are based on previous recommendations.

Ischemia causes reversible or irreversible damage in the brain, eg, sudden disorganized electrical activity, which can cause subsequent seizures. Two types of seizures after ischemic stroke can be distinguished: EPSS, which occurs up to 7 days after AIS and late remote seizures, which appear between the seventh day and the second year after AIS onset. ${ }^{31}$ The EPSS and LPSSs have different pathophysiology. The early one may be a consequence of ischemia, which increases the extracellular concentration of glutamic acid. Glutamate as a dominant neurotransmitter stimulates the adult brain, and its elevated level contributes to excitotoxic brain damage. ${ }^{32} \mathrm{On}$ the other hand, late remote PSS appears as a consequence of damage caused by ischemia and exposure to the subsequent increased level of glutamate, which may be related to secondary neuronal injury. ${ }^{33}$ LPSSs are also suggested to result from gliosis and the development of a meningocerebral cicatrix. ${ }^{5}$ Previously, in rats, it was also observed that hyperglycemia at the time of brain ischemia may influence epileptogenesis. ${ }^{34}$

However, the time of the onset of early and late seizures is unequivocal. In the study by Breitweg et al, ${ }^{24}$ PSS was classified as the early one when it occurred during the first 48 hours after the onset of stroke symptoms and the authors recognized patients as epileptic when they experienced two or more seizures beyond the time limit of early seizures. On the other hand, in a group of almost 500 patients with AIS from the Czech Republic, seizures, which occurred up to 2 weeks after stroke, were considered to be early. ${ }^{35}$ Similarly, Strzelczyk et a ${ }^{36}$ attributed seizures to the early period if they occurred up to 14 days after stroke. In the case of PSE, it can be identified in a patient who had at least two recurrent seizures, which were not provoked by any factor (metabolic, toxic, or any other) and occurred after the acute phase of stroke. ${ }^{31,37}$ But again, a problem regarding the time of seizure occurrence after ischemic stroke, which clearly allows for the diagnosis of PSE, needs to be resolved. According to Hesdorffer et al, ${ }^{38}$ acute symptomatic seizures cannot be recognized as epilepsy since they carry a lower risk of subsequent unprovoked seizures. We found one study giving the cutoff point for PSE, but the study was conducted in 2005 so much earlier before the current recommendations. ${ }^{13}$ According to its authors, PSE can be diagnosed if a patient had two or more seizures after stroke and was subsequently treated with AEDs to achieve seizure control within the follow-up period of mean 7 years. ${ }^{13}$ Furthermore, in one study, we found a definition of very late seizures, instead of epilepsy, which referred to patients who had their first seizure $>2$ years after stroke. ${ }^{8}$

\section{Predictors and genetic risk factors for PSS and PSE}

Different sets of risk factors for PSS and PSE can be distinguished in patients with stroke. In adults, the most often demonstrated predictors are the stroke subtype, infarct size, location, and severity of ischemia. However, due to the different criteria of recruitment, the length of follow-up, as well as differences in the time of establishing EPSS and LPSS, inconsistent and even contradictory results are given on the topic.

In adults, Jungehulsing et a ${ }^{16}$ observed that hypertension and stroke severity were significant predictors for PSE. In turn, in the study based on German patients, no relations between some metabolic factors and development of seizures were found. ${ }^{26}$ Surprisingly, according to the data of Devuyst et al, ${ }^{39}$ an elevated level of cholesterol may play a protective role in seizures and ischemic stroke. Moreover, Roivainen et al observed that cigarette smoking, heavy drinking, as well as infections preceding stroke were more frequent in patients having LPSS compared to patients with acute symptomatic seizures (up to 7 days after stroke onset). ${ }^{12}$ Univariate analysis performed by Conrad et al demonstrated that younger age of patients was associated with the occurrence of seizures. ${ }^{26}$ Similar findings were reported by other authors. ${ }^{40}$ In contrast, earlier data showed that patients aged $>84$ years had a higher risk of PSS. ${ }^{41}$ This may result from decreased excitability of the cortex due to the aging process of brain tissue.

Other factors that increase the risk of PSE include the volume of infarcts (the larger the stroke, the greater the probability of having PSE), stroke severity, and location of infarcts (cortical location carries a greater risk of PSE). ${ }^{42-44}$ In the study by Misirli et al, the most important risk factor for the development of seizures was cortical involvement with the OR equal to $4.25 .^{40}$ In turn, Conrad et al observed that cortical involvement is associated with late seizures. ${ }^{26}$ Some discrepancies may be noted in the context of correlations between the cortical location of stroke and the development of EPSS; some authors found such a relation while others did not. ${ }^{45,46}$ No significant difference in the location of stroke was also found between patients with and without PSS. ${ }^{35}$ Very interesting results were reported by Cordonnier et al, who demonstrated that preexisting dementia was independently 
related to the appearance of late seizures $(\mathrm{OR}=4.66)$, but not to early seizures. ${ }^{11}$ This finding may be explained by some dysfunction of glutamate pathways in people with dementia.

Hesdorffer et al observed that the risk of subsequent unprovoked seizures is higher in the case of the occurrence of LPSS than in the case of early symptomatic seizures. ${ }^{38}$ The results of a Korean study indicated that some factors determining the high risk of the second seizure after the first one may emerge; the patients who are mostly endangered by the second seizure after the first one in follow-up are characterized by male gender, age below 65 years, large ischemic lesions, and focal seizures in clinical presentation. ${ }^{47}$ This may be helpful in making individual decisions about treatment administration after the first seizure.

The latest data also show that intravenous tissue plasminogen activator therapy, which is approved for acute stroke treatment, may be a risk factor for subsequent $\mathrm{PSE}^{48}$ since it is suggested to cause some neurotoxicity. Likewise, using antidepressants was a significant risk factor for LPSS in the Finnish population, whereas using antipsychotic or anxiolytic medications characterized patients with both acute seizure and LPSS. ${ }^{12}$ One of the suggested risk factors for PSE is also hemorrhagic transformation. ${ }^{6,12}$ In our opinion, a family history of epilepsy should also be taken into account as a risk factor for PSE since genes contribute to epileptogenesis.

The most often indicated predictors for PSS and epilepsy in pediatric population are, among others, age at the time of stroke, focal cerebral arteriopathy of childhood, and the number of infarct foci. ${ }^{17}$ In this study, all patients who experienced late remote PSS were diagnosed as epileptic. ${ }^{17}$ Similar findings were reported by Lee et al, who also observed that epilepsy was diagnosed in $100 \%$ of children with late seizures. ${ }^{7}$ Fox et $\mathrm{al}^{25}$ also demonstrated that younger age may be a predictor for poststroke remote seizures. Additionally, according to the authors, children presenting acute seizures at the time of stroke also had an increased risk of remote seizures, compared to children with no seizure at the time of stroke ( $\mathrm{HR}=4.1)$, as well as an increased risk of developing active epilepsy $(\mathrm{HR}=4.2) .{ }^{25}$ An American study on children with AIS demonstrated that younger children were more likely to present with seizures at stroke ictus. ${ }^{18}$ Acute symptomatic seizures were also predictors for late remote seizures and epilepsy in this study. ${ }^{18}$ Breitweg et al also reported young age, cortical involvement, and early seizures as predictors for PSE in the group of pediatric patients from Epilepsy Center for Children and Adolescents in Vogtareuth (Germany). ${ }^{24}$

Searching for genetic risk factors for PSS and epilepsy is not common yet important. Recently, a few studies regarding the role of polymorphic genetic variants in PSE in adult and pediatric patients have been published. ${ }^{49-53}$ Yang et $\mathrm{al}^{49}$ analyzed the $A L D H 2$ rs671 polymorphism in 732 individuals who were divided into three subgroups: PSE patients, ischemic stroke patients, and healthy controls. Mitochondrial ALDH2 is an enzyme expressed in many tissues of the body, including the brain, which metabolizes reactive aldehydes to acetic acid and also detoxifies aldehyde adducts generated by reactive oxygen species. The rs671 polymorphism decreases ALDH 2 activity by $90 \%$. The authors found a significant difference in the prevalence of genotypes and alleles of the rs671 polymorphism between patients with PSE and patients with ischemic stroke. Patients with the A allele of the rs671 polymorphism had also significantly higher levels of plasma 4-hydroxynonenal (4-HNE), which is an ALDH2 substrate, and its elevated level is involved in cerebral ischemia. ${ }^{49}$ In turn, Zhang et $\mathrm{al}^{50}$ found a significant role of the $\mathrm{T}$ allele of the CD40-1 C/T polymorphism in PSE susceptibility in adult patients. The $\mathrm{T}$ allele was observed in $50.5 \%$ of patients with PSE in comparison with $38.5 \%$ patients with ischemic stroke. The authors classified patients into the group of PSE based on clinical symptoms and positive electroencephalogram (EEG) performance. Patients with PSE also showed a higher level of plasma $\mathrm{sCD} 40 \mathrm{~L}$ and increased expression of CD40, both of which are reflected in prothrombotic conditions as well as oxidative stress. ${ }^{50}$

In children suffering from ischemic stroke, an association between the $\mathrm{G}$ allele carrier-state in the $-174 \mathrm{G}>\mathrm{C}$ polymorphism in IL6 gene and PSE was demonstrated. ${ }^{51}$ The CC homozygotes were not found in children with stroke and subsequent epilepsy, whereas the CC genotype was observed in about $25 \%$ of children without PSE. A number of proinflammatory molecules can be released due to some brain injury (probably also as a result of ischemia) or proconvulsant events, which can activate microglia and astrocytes. ${ }^{54}$ These proinflammatory mediators may cause changes in neuronal excitability and then neuronal communications. Other interesting pilot data showed that the AA genotype of the $1298 \mathrm{~A}>\mathrm{C}$ polymorphism within the MTHFR gene may have a protective role in the development of seizures after stroke in pediatric patients (AA genotype was observed in almost $19 \%$ of children with seizures and in $43 \%$ of children without seizures). ${ }^{52}$ The $1298 \mathrm{~A}>\mathrm{C}$ polymorphism results in a decreased activity of MTHFR, but to a lesser extent than in the case of the MTHFR677C $>\mathrm{T}$ polymorphism. The decreased activity of the enzyme results in the elevated homocysteine level, which was suggested to cause neuronal excitotoxicity through overstimulation of the receptors of 
$N$-methyl-D-aspartate. ${ }^{55}$ Another study demonstrated that TT homozygotes of the rs2516839 polymorphism within the USF-1 gene, which is involved in lipid metabolism, were more frequent in AIS children with PSE. ${ }^{53}$ Previously, the results of an experimental study by Sirito et $\mathrm{al}^{56}$ showed the role of USF in normal brain function since the USF-deficient mice experienced spontaneous epileptic seizures.

\section{Current and future treatment of PSS and PSE}

In developed countries at least one out of ten stroke survivors will suffer from epilepsy. ${ }^{1}$ However, even if the risk of seizures and epilepsy after stroke is high, the American Heart Association does not recommend the prophylaxis using AEDs in stroke survivors. ${ }^{57}$ The role of some new generation AEDs is being postulated in epileptogenesis prevention. In a rat model of epilepsy, levetiracetam (LEV) reduced gliosis in hippocampus and piriform cortex. ${ }^{58}$ Then perampanel, a novel selective, noncompetitive AMPA glutamate receptor antagonist, was suggested as a potential epilepetogenesis blocker by reducing glutamate excitotoxicity. ${ }^{59}$ Also aspirin and rapamycin, due to their anti-inflammatory action, are considered in the prevention of poststroke epileptogenesis. ${ }^{60,61}$

Finally statins, commonly used in patients with cardiovascular disorders, show anticonvulsant and anti-inflammatory action, with reduction of the brain-blood barrier destruction in the acute phase of ischemic stroke. According to available data, statin administration not only reduces the development of PSE but also leads to a reduction in the number of hospitalizations due to epilepsy in patients with stroke. ${ }^{62,63}$

Even though the probability of subsequent unprovoked seizures after the first PSS is quite high in poststroke patients, the prophylaxis of the recurrent seizures with AEDs is not commonly practised. ${ }^{47}$ According to Tanaka et al, in Japan $33 \%$ of hospitals prescribe AEDs after the first late seizure compared to $88 \%$ prescribing AEDs after the second one. ${ }^{64}$ The exception would be the patients after status epilepticus as the first epilepsy manifestation. ${ }^{65}$ Although the early AED administration in poststroke patients does not modify the pathogenesis of the disease and prognosis, it may prevent the second seizure occurrence, especially that the risk of recurrent seizures after the first late-onset PSS is high and estimated at about one-third of patients. ${ }^{47,66}$ In turn, in the study by Ahangar et al, ${ }^{5}$ phenobarbital (PB) or phenytoin (PHT) was prescribed very early, ie, to each patient who had early- and late-onset PSS. The authors explain the later lower frequency of recurrent seizures with this early inclusion of anticonvulsant treatment.
According to some data, antiepileptic treatment should be administered after the first late-onset PSS. ${ }^{67}$ One of the proposed drugs to treat adult patients after the first late-onset seizure is gabapentin (GBP) at a daily dose of 900-1,800 mg; following the patients within 30 months, the authors observed recurrence of seizures in about $18 \%$ of the examined group. The side effects requiring drug withdrawal were observed in $<3 \%$ of patients. ${ }^{67}$ Oros et al demonstrated that repeated epileptic attacks concerned $27 \%$ of patients with AIS taking anticonvulsants during 1 year after the first PSS and almost $54 \%$ of patients taking no antiepileptic treatment. ${ }^{68}$

PSE in most patients is successfully treated with monotherapy. ${ }^{69}$ As the seizures in PSE are naturally focal, carbamazepine (CBZ) and GBP administration is the firstline drug treatment in adults in Europe, whereas in the United States, the drugs of first choice in these patients are PHT and GBP. ${ }^{68,70-73}$ Still, in Japanese patients with PSE, administration of valproic acid (VPA) as the first-line drug is more common because the second-generation AEDs are not officially approved in this country.9,66

In the randomized noncontrolled study by Gilard et al comparing the efficacy and side effects of lamotrigine (LTG) vs $\mathrm{CBZ}$, the first one was more effective and the patients treated with LTG reported fewer side effects. ${ }^{74}$ The efficacy comparison between LEV and CBZ did not reveal any significant advantage of one of the drugs, but LEV was better tolerated. ${ }^{75}$ Taiwanese authors compared the action of VPA, PHT, CBZ, and new AEDs (oxcarbazepine [OXC], vigabatrin, tiagabine, LTG, TPM, GBP, LEV, and pregabaline) in patients with PSE. In $>3,000$ patients treated with these AEDs, the number of hospitalizations for seizure exacerbation was lower in the individuals treated with VPA and new AEDs than in those treated with PHT. ${ }^{76}$

According to Billinghurst et al, acute seizures in AIS children were most commonly treated with LEV, PB, OXC, and PHT $(62 \%, 46 \%, 8 \%$, and $8 \%$, respectively). Nearly one-fourth of the patients needed more than one of the AEDs at discharge. ${ }^{18}$

The prognosis in adult onset PSE seems rather favorable. Stephen et al followed a group of patients with PSE during the period of 2 years; most of the patients required only one AED and at the end of the second year of observation, up to $67 \%$ of the patients were seizure free. ${ }^{77}$

Contrary to adult patients suffering from PSE, no research comparing different AEDs in pediatric population was found by the authors. Data from the study by Fox et a ${ }^{25}$ showed that all children with remote seizures were treated with AEDs and most of them took at least two AEDs. 
However, despite this, the last follow-up showed that $>30 \%$ of children with active PSE had recent seizures. ${ }^{25}$ In pediatric patients meeting the criteria of drug-resistant epilepsy, the operative procedure, mainly peri-insular hemispherotomy, should be taken into consideration without hesitance not only for its favorable antiepileptic action but also for better social and behavioral outcome. ${ }^{78}$

However, too early antiepileptic treatment, especially in children suffering from stroke and having early seizures after ischemia, may have an adverse effect on their motor function and the whole process of recovery. Such data based on animal models were previously published in regard to PHT, $\mathrm{PB}$, and diazepam. ${ }^{79-81}$ On the other hand, the hypothesis of attenuation of ischemic brain injury by anticonvulsants is also analyzed. Markowitz et $\mathrm{al}^{82}$ observed that a lower dose of $\mathrm{PB}$ may be more protective against the consequences of ischemia in immature CD1 mice with induced ischemia compared to a higher dose. The lower dose of PB reduced acute seizures and chronic brain injury and restored normal weight gain and exploratory behavior. ${ }^{82}$

\section{Conclusion}

The pathogenesis of PSE is still not fully understood, but ischemic stroke is undoubtedly one of the most common reasons for epilepsy in adults. For effective prevention of PSS and epilepsy, risk factors should be reliable and easily measured or detected in patients. Different risk factors as well as interactions between them are probably related to the development of PSE in a particular patient. At the moment, it is difficult to predict which patients suffering from ischemic stroke will have seizures. Recent data demonstrate that attempts to personalize the approach for assessing the risk of LPSS in AIS patients are being made. ${ }^{83}$ Galovic et al developed a multivariate model named "SeLECT", based on five risk factors, ie, severity of stroke, large-artery atherosclerotic aetiology, early seizures, cortical involvement, and territory of middle cerebral artery involvement, to evaluate the risk of late seizures within the first year after stroke. ${ }^{83}$ The study was performed in a cohort of 1,200 patients with AIS, and according to the authors, the results are promising since the SeLECT model can predict the late seizures and can be smartphone operated. ${ }^{83}$ On the other hand, some doubts regarding the assumptions of this model have also been commented on. ${ }^{84}$

In presuming the occurrence of PSS, the role of EEG is also analyzed. The latest data show that the first EEG asymmetry can independently predict unprovoked seizures or epilepsy in the year following anterior circulation ischemic stroke. ${ }^{85}$ On the other hand, from a practical point of view, the asymmetry of EEG track in poststroke patients is just the result of ischemic brain injury and should be considered a potential PSE risk factor coexisting with others.

All this shows the complexity of the causes of PSE and its prediction. Thus, the more knowledge on PSE, the more advanced, precise, or even individualized therapies will have the chance to be implemented. However, in the light of the reviewed data, the authors believe that the definition of PSE itself needs to be first refined and standardized, otherwise knowing the risk factors or the actual frequency of the disease will still be a problem.

\section{Disclosure}

The authors report no conflicts of interest in this work.

\section{References}

1. Hauser WA, Annegers JF, Kurland LT. Incidence of epilepsy and unprovoked seizures in Rochester, Minnesota: 1935-1984. Epilepsia. 1993;34(3):453-458.

2. Chadehumbe MA, Khatri P, Khoury JC, et al. Seizures are common in the acute setting of childhood stroke: a population-based study. J Child Neurol. 2009;24(1):9-12.

3. Yang H, Rajah G, Guo A, Wang Y, Wang Q. Pathogenesis of epileptic seizures and epilepsy after stroke. Neurol Res. 2018;40(6):426-432.

4. Burneo JG, Fang J, Saposnik G; Investigators of the Registry of the Canadian Stroke Network. Impact of seizures on morbidity and mortality after stroke: a Canadian multi-centre cohort study. Eur J Neurol. 2010;17(1):52-58.

5. Ahangar AA, Hosseini S, Saghebi R. Clinical features of post stroke seizure in Babol, northern Iran. Neurosciences. 2008;13(1):88-90.

6. Alberti A, Paciaroni M, Caso V, Venti M, Palmerini F, Agnelli G. Early seizures in patients with acute stroke: frequency, predictive factors, and effect on clinical outcome. Vasc Health Risk Manag. 2008;4(3): 715-720.

7. Lee JC, Lin KL, Wang HS, et al. Seizures in childhood ischemic stroke in Taiwan. Brain Dev. 2009;31(4):294-299.

8. De Reuck J, Sieben A, Van Maele G. Characteristics and outcomes of patients with seizures according to the time of onset in relation to stroke. Eur Neurol. 2008;59(5):225-228.

9. Okuda S, Takano S, Ueno M, Hamaguchi H, Kanda F. Clinical features of late-onset poststroke seizures. J Stroke Cerebrovasc Dis. 2012;21(7): $583-586$.

10. Kwan J. Stroke: predicting the risk of poststroke epilepsy - why and how? Nat Rev Neurol. 2010;6(10):532-533.

11. Cordonnier C, Hénon H, Derambure P, Pasquier F, Leys D. Influence of pre-existing dementia on the risk of post-stroke epileptic seizures. J Neurol Neurosurg Psychiatry. 2005;76(12):1649-1653.

12. Roivainen R, Haapaniemi E, Putaala J, Kaste M, Tatlisumak T. Young adult ischaemic stroke related acute symptomatic and late seizures: risk factors. Eur J Neurol. 2013;20(9):1247-1255.

13. Kammersgaard LP, Olsen TS. Poststroke epilepsy in the Copenhagen stroke study: incidence and predictors. J Stroke Cerebrovasc Dis. 2005; 14(5):210-214.

14. Kamble S, Srivastava T, Sardana V. Clinical and radiological profile of post stroke seizures. Ind J Neurosci. 2017;3(1):8-12.

15. Chen TC, Chen YY, Cheng PY, Lai CH. The incidence rate of poststroke epilepsy: a 5-year follow-up study in Taiwan. Epilepsy Res. 2012; 102(3): 188-194.

16. Jungehulsing GJ, Heuschmann PU, Holtkamp M, Schwab S, KolominskyRabas PL. Incidence and predictors of post-stroke epilepsy. Acta Neurol Scand. 2013;127(6):427-430. 
17. Kopyta I, Sarecka-Hujar B, Skrzypek M. Post-stroke epilepsy in Polish paediatric patients. Dev Med Child Neurol. 2015;57(9):821-828.

18. Billinghurst LL, Beslow LA, Abend NS, et al. Incidence and predictors of epilepsy after pediatric arterial ischemic stroke. Neurology. 2017; 88(7):630-637.

19. Pilarska E, Lemka M. Epileptic seizures and epilepsy in ischemic stroke in children. Neurol Dziec. 2007;16:23-27.

20. Nasiri J, Ariyana A, Yaghini O, Ghazavi MR, Keikhah M, Salari M. Neurological outcome after arterial ischemic stroke in children. $A d v$ Biomed Res. 2016;5:107.

21. Lee EH, Yum MS, Ko TS. Risk factors and clinical outcomes of childhood ischemic stroke in a single Korean tertiary care center. J Child Neurol. 2012;27(4):485-491.

22. De Schryver EL, Kappelle LJ, Jennekens-Schinkel A, Boudewyn Peters AC. Prognosis of ischemic stroke in childhood: a long-term follow-up study. Dev Med Child Neurol. 2000;42(5):313-318.

23. Morais NM, Ranzan J, Riesgo RS. Predictors of epilepsy in children with cerebrovascular disease. J Child Neurol. 2013;28(11):1387-1391.

24. Breitweg I, Stülpnagel CV, Pieper T, et al. Early seizures predict the development of epilepsy in children and adolescents with stroke. Eur J Paediatr Neurol. 2017;21(3):465-467.

25. Fox CK, Glass HC, Sidney S, Lowenstein DH, Fullerton HJ. Acute seizures predict epilepsy after childhood stroke. Ann Neurol. 2013; 74(2):249-256.

26. Conrad J, Pawlowski M, Dogan M, Kovac S, Ritter MA, Evers S. Seizures after cerebrovascular events: risk factors and clinical features. Seizure. 2013;22(4):275-282.

27. Myint PK, Staufenberg EF, Sabanathan K. Post-stroke seizure and post-stroke epilepsy. Postgrad Med J. 2006;82(971):568-572.

28. ILAE (International League against Epilepsy). Commission on Classification and Terminology. Proposal for revised clinical and electroencephalographic classification of epileptic seizures. Epilepsia. 1981;22:489-501.

29. Berg AT, Scheffer IE. New concepts in classification of the epilepsies: entering the 21st century. Epilepsia. 2011;52(6):1058-1062.

30. Fisher RS, Acevedo C, Arzimanoglou A, et al. ILAE Official Report: a practical clinical definition of epilepsy. Epilepsia. 2014;55(4):475-482.

31. Beslow LA, Abend NS, Gindville MC, et al. Pediatric intracerebral hemorrhage: acute symptomatic seizures and epilepsy. JAMA Neurol. 2013;70(4):448-454.

32. Barker-Haliski M, White HS. Glutamatergic mechanisms associated with seizures and epilepsy. Cold Spring Harb Perspect Med. 2015; 5(8):a022863.

33. Luhmann HJ. Ischemia and lesion induced imbalances in cortical function. Prog Neurobiol. 1996;48(2):131-166.

34. Uchino H, Smith ML, Bengzon J, Lundgren J, Siesjö BK. Characteristics of postischemic seizures in hyperglycemic rats. J Neurol Sci. 1996; 139(1):21-27.

35. Bryndziar T, Sedova P, Kramer NM, et al. Seizures following ischemic stroke: frequency of occurrence and impact on outcome in a long-term population-based study. J Stroke Cerebrovasc Dis. 2016;25(1):150-156.

36. Strzelczyk A, Haag A, Raupach H, Herrendorf G, Hamer HM, Rosenow F. Prospective evaluation of a post-stroke epilepsy risk scale. J Neurol. 2010;257(8):1322-1326.

37. Zelano J, Lundberg RG, Baars L, Hedegärd E, Kumlien E. Clinical course of poststroke epilepsy: a retrospective nested case-control study. Brain Behav. 2015;5(9):e00366.

38. Hesdorffer DC, Benn EK, Cascino GD, Hauser WA. Is a first acute symptomatic seizure epilepsy? Mortality and risk for recurrent seizure. Epilepsia. 2009;50(5):1102-1108.

39. Devuyst G, Karapanayiotides T, Hottinger I, van Melle G, Bogousslavsky J. Prodromal and early epileptic seizures in acute stroke: does higher serum cholesterol protect? Neurology. 2003;61(2): 249-252.

40. Misirli H, Özge A, Somay G, Erdoğan N, Erkal H, Erenoğlu NY. Seizure development after stroke. Int J Clin Pract. 2006;60(12):1536-1541.
41. Burn J, Dennis M, Bamford J, Sandercock P, Wade D, Warlow C. Epileptic seizures after a first stroke: the Oxfordshire Community Stroke Project. BMJ. 1997;315(7122):1582-1587.

42. Zelano J. Poststroke epilepsy: update and future directions. Ther $A d v$ Neurol Disord. 2016;9(5):424-435.

43. Beghi E, D'Alessandro R, Beretta S, et al. Incidence and predictors of acute symptomatic seizures after stroke. Neurology. 2011;77(20): 1785-1793.

44. Kulhari A, Strbian D, Sundararajan S. Illustrative teaching case: early onset seizures in stroke. Stroke. 2014;45:e249-e251.

45. Lamy C, Domigo V, Semah F; Patent Foramen Ovale and Atrial Septal Aneurysm Study Group. Early and late seizures after cryptogenic ischemic stroke in young adults. Neurology. 2003;60:400-404.

46. Reith J, Jørgensen HS, Nakayama H, Raaschou HO, Olsen TS. Seizures in acute stroke: predictors and prognostic significance. Stroke. 1997; 28(8):1585-1589.

47. Kim HJ, Park KD, Choi KG, Lee HW. Clinical predictors of seizure recurrence after the first post-ischemic stroke seizure. BMC Neurol. 2016;16(1):212

48. Naylor J, Thevathasan A, Churilov L, et al. Association between different acute stroke therapies and development of post stroke seizures. BMC Neurol. 2018;18(1):61.

49. Yang H, Song Z, Yang GP, et al. The ALDH2 rs671 polymorphism affects post-stroke epilepsy susceptibility and plasma 4-HNE levels. PLoS One. 2014;9(10):e109634.

50. Zhang B, Chen M, Yang H, Wu T, Song C, Guo R. Evidence for involvement of the CD40/CD40L system in post-stroke epilepsy. Neurosci Lett. 2014;567:6-10.

51. Balcerzyk A, Nowak M, Kopyta I, et al. Impact of the $-174 \mathrm{G} / \mathrm{C}$ interleukin-6 (IL-6) gene polymorphism on the risk of paediatric ischemic stroke, its symptoms and outcome. Folia Neuropathol. 2012; 50(2): 147-151.

52. Smulska N. Outcome after pediatric stroke: investigation genes polymorphism. Eur J Ped Neurol. 2015;19(Suppl 1):S151-S152.

53. Balcerzyk A, Niemiec $P$, Iwanicki $T$, et al. Upstream stimulating factor 1 (USF-1) gene polymorphisms and the risk, symptoms, and outcome of pediatric ischemic stroke. J Stroke Cerebrovasc Dis. 2018;27(7): $1885-1889$.

54. Vezzani A, Aronica E, Mazarati A, Pittman QJ. Epilepsy and brain inflammation. Exp Neurol. 2013;244:11-21.

55. Lipton SA, Kim WK, Choi YB, et al. Neurotoxicity associated with dual actions of homocysteine at the N-methyl-D-aspartate receptor. Proc Natl Acad Sci. 1997;94(11):5923-5928.

56. Sirito M, Lin Q, Deng JM, Behringer RR, Sawadogo M. Overlapping roles and asymmetrical cross-regulation of the USF proteins in mice. Proc Natl Acad Sci. 1998;95(7):3758-3763.

57. Winstein CJ, Stein J, Arena R, et al. Guidelines for adult stroke rehabilitation and recovery: a guideline for healthcare professionals from the American Heart Association/American Stroke Association. Stroke. 2016;47(6):e98-e169.

58. Kim JE, Choi HC, Song HK, et al. Levetiracetam inhibits interleukin-1 beta inflammatory responses in the hippocampus and piriform cortex of epileptic rats. Neurosci Lett. 2010;471(2):94-99.

59. Ceolin L, Bortolotto ZA, Bannister N, Collingridge GL, Lodge D, Volianskis A. A novel anti-epileptic agent, perampanel, selectively inhibits AMPA receptor-mediated synaptic transmission in the hippocampus. Neurochem Int. 2012;61(4):517-522.

60. Ma L, Cui XL, Wang Y, et al. Aspirin attenuates spontaneous recurrent seizures and inhibits hippocampal neuronal loss, mossy fiber sprouting and aberrant neurogenesis following pilocarpine-induced status epilepticus in rats. Brain Res. 2012;1469:103-113.

61. Sunnen CN, Brewster AL, Lugo JN, et al. Inhibition of the mammalian target of rapamycin blocks epilepsy progression in NS-Pten conditional knockout mice. Epilepsia. 2011;52(11):2065-2075

62. Guo J, Guo J, Li J, et al. Statin treatment reduces the risk of poststroke seizures. Neurology. 2015;85(8):701-707. 
63. Etminan M, Samii A, Brophy JM. Statin use and risk of epilepsy: a nested case-control study. Neurology. 2010;75(17):1496-1500.

64. Tanaka T, Ihara M. Post-stroke epilepsy. Neurochem Int. 2017;107:219-228.

65. Beleza P. Acute symptomatic seizures: a clinically oriented review. Neurologist. 2012;18(3):109-119.

66. Tanaka T, Yamagami H, Ihara M, et al. Seizure outcomes and predictors of recurrent post-stroke seizure: a retrospective observational cohort study. PLoS One. 2015;10(8):e0136200.

67. Alvarez-Sabín J, Montaner J, Padró L, et al. Gabapentin in late-onset poststroke seizures. Neurology. 2002;59(12):1991-1993.

68. Oros MM, Smolanka VI, Sofilkanich NV, Borovik OI, Luts VV, Andrukh PG. Epilepsy after ishemic stroke: is it worth administering anticonvulsants after the first attack? Wiad Lek. 2018;71(2 Pt 1): 269-272.

69. Silverman IE, Restrepo L, Mathews GC. Poststroke seizures. Arch Neurol. 2002;59(2):195-202.

70. Inoue Y, Nakamura F, Nishida T. Treatment guidelines for adult epilepsy. Rinsho Shinkeigaku. 2004;44(11):861-864

71. Pugh MJ, Van Cott AC, Cramer JA, et al. Trends in antiepileptic drug prescribing for older patients with new-onset epilepsy: 2000-2004. Neurology. 2008;70(22 Pt 2):2171-2178.

72. Pugh MJ, Knoefel JE, Mortensen EM, Amuan ME, Berlowitz DR, van Cott AC. New-onset epilepsy risk factors in older veterans. $J$ Am Geriatr Soc. 2009;57(2):237-242.

73. Johnell K, Fastbom J. Antiepileptic drug use in community-dwelling and institutionalized elderly: a nationwide study of over 1,300,000 older people. Eur J Clin Pharmacol. 2011;67(10):1069-1075.

74. Gilad R, Sadeh M, Rapoport A. Monotherapy of lamotrigine versus carbamazepine in patients with poststroke seizure. Clin Neuropharmacol. 2007;30(4):189-195.

75. Consoli D, Bosco D, Postorino P, et al. Levetiracetam versus carbamazepine in patients with late poststroke seizures: a multicenter prospective randomized open-label study (EpIC Project). Cerebrovasc Dis. 2012; 34(4):282-289.
76. Huang YH, Chi NF, Kuan YC, et al. Efficacy of phenytoin, valproic acid, carbamazepine and new antiepileptic drugs on control of late-onset post-stroke epilepsy in Taiwan. Eur J Neurol. 2015;22(11):1459-1468.

77. Stephen LJ, Kwan P, Brodie MJ. Does the cause of localisationrelated epilepsy influence the response to antiepileptic drug treatment? Epilepsia. 2001;42(3):357-362.

78. Scavarda D, Major P, Lortie A, Mercier C, Carmant L. Periinsular hemispherotomy in children with stroke-induced refractory epilepsy. J Neurosurg Pediatr. 2009;98(2):115-120.

79. Brailowsky S, Knight RT, Efron R. Phenytoin increases the severity of cortical hemiplegia in rats. Brain Res. 1986;376(1):71-77.

80. Hernandez TD, Russell LC. Phenobarbital delays recovery from cortex damage. Soc Neurosci Abstr. 1992;18:870.

81. Schallert T, Hernandez TD, Barth TM. Recovery of function after brain damage: severe and chronic disruption by diazepam. Brain Res. 1986; 379(1):104-111.

82. Markowitz GJ, Kadam SD, Smith DR, Johnston MV, Comi AM. Different effects of high- and low-dose phenobarbital on post-stroke seizure suppression and recovery in immature CD1 mice. Epilepsy Res. 2011; 94(3):138-148.

83. Galovic M, Döhler N, Erdélyi-Canavese B, et al. Prediction of late seizures after ischaemic stroke with a novel prognostic model (the SeLECT score): a multivariable prediction model development and validation study. Lancet Neurol. 2018;17(2):143-152.

84. Finsterer J. The SeLECT score is inappropriate to predict post-stroke epilepsy. Lancet Neurol. 2018;17(2):106-107.

85. Bentes C, Martins H, Peralta AR, et al. Early EEG predicts poststroke epilepsy. Epilepsia Open. 2018;3(2):203-212.
Neuropsychiatric Disease and Treatment

\section{Publish your work in this journal}

Neuropsychiatric Disease and Treatment is an international, peerreviewed journal of clinical therapeutics and pharmacology focusing on concise rapid reporting of clinical or pre-clinical studies on a range of neuropsychiatric and neurological disorders. This journal is indexed on PubMed Central, the 'PsycINFO' database and CAS,

\section{Dovepress}

and is the official journal of The International Neuropsychiatric Association (INA). The manuscript management system is completely online and includes a very quick and fair peer-review system, which is all easy to use. Visit http://www.dovepress.com/testimonials.php to read real quotes from published authors. 